Case Report

\title{
Hypercalcemia, Anemia, and Acute Kidney Injury: A Rare Presentation of Sarcoidosis
}

\author{
Neeraj Sharma, ${ }^{1}$ Hassan Tariq, ${ }^{1}$ Kalpana Uday, ${ }^{1}$ Yevgeniy Skaradinskiy, ${ }^{1}$ \\ Masooma Niazi, ${ }^{2}$ and Sridhar Chilimuri ${ }^{1}$ \\ ${ }^{1}$ Department of Medicine, Bronx Lebanon Hospital Center, 1650 Selwyn Avenue, Suite No. 10C, Bronx, NY 10457, USA \\ ${ }^{2}$ Department of Pathology, Bronx Lebanon Hospital Center, 1650 Grand Concourse, Bronx, NY 10457, USA
}

Correspondence should be addressed to Hassan Tariq; htariq@bronxleb.org

Received 18 March 2015; Accepted 14 June 2015

Academic Editor: Jagdish Butany

Copyright (c) 2015 Neeraj Sharma et al. This is an open access article distributed under the Creative Commons Attribution License, which permits unrestricted use, distribution, and reproduction in any medium, provided the original work is properly cited.

\begin{abstract}
We discuss a case of a 61-year-old woman who presented with substernal chest pain. She was found to have elevated calcium levels, anemia, and acute kidney injury. The hypercalcemia persisted despite therapy with fluids and bisphosphonates. She was found to have nonparathyroid hormone (PTH) mediated hypercalcemia. The chest X-ray did not reveal any pathology. Our Initial impression was likely underlying hematologic malignancy such as lymphoma or multiple myeloma. A bone marrow biopsy was performed that revealed nonnecrotizing granulomatous inflammation. Further workup revealed elevated vitamin 1,25 dihydroxy level, beta-two microglobulin level, and ACE levels. Noncontrast computed tomography (CT) scan of chest showed bilateral apical bronchiectasis, but did not show any lymphadenopathy or evidence of malignancy. Subsequently, a fiber optic bronchoscopy with transbronchial biopsy showed nonnecrotizing granulomatous inflammation consistent with sarcoidosis. After initiating glucocorticoid therapy, the patient's hypercalcemia improved and her kidney function returned to baseline.
\end{abstract}

\section{Introduction}

Sarcoidosis is a chronic systemic disease of unknown etiology that is characterized by the formation of immune granulomas in various organs [1]. Although hypercalcemia is a known metabolic complication of sarcoidosis (10-20 percent of patients), it is rarely a presenting manifestation, with clinically significant hypercalcemia occurring in less than $5 \%$ of patients [2]. Among the granulomatous disorders, sarcoidosis and tuberculosis are the most common etiologies $[3,4]$. Approximately 10-20 percent of patients with sarcoidosis have hypercalcemia [4]. Regardless of the etiology, the complications of hypercalcemia include nephrolithiasis, nephrocalcinosis, nephrogenic diabetes insipidus, renal insufficiency, and polyuria. However, many patients with hypercalcemia and granulomatous disease are asymptomatic. It has been purposed that increased intestinal calcium absorption, induced by high 1,25-dihydroxyvitamin $\mathrm{D}$, is the main abnormality contributing to elevated serum calcium levels. Normally, hypercalcemia suppresses release of
PTH and thus calcitriol production; however, in sarcoidosis, activated macrophages produce calcitriol independent of PTH $[5,6]$. Furthermore, parathyroid hormone-related protein (PTHrp), which is the usual etiologic agent of humoral hypercalcemia of malignancy, has also been implicated to contribute to hypercalcemia in sarcoidosis [6]. Although sarcoidosis is more prevalent in the African-American population, hypercalcemia is more commonly found in the Caucasian population with sarcoidosis [7]. Here we report a case of a patient who presented with hypercalcemia, anemia, and acute kidney injury who was subsequently diagnosed with sarcoidosis.

\section{Case Presentation}

A 61-year-old woman presented to the emergency department of our hospital with complaint of substernal chest pain for one day. Chest pain was described as being sharp, 7/10 in intensity, being nonradiating, and being with no aggravating or alleviating factors. Chest pain was not associated with any 
TABLE 1: Laboratory values on admission (reference range in parenthesis).

\begin{tabular}{|c|c|c|}
\hline Laboratory test & Results on admission & SI units \\
\hline White blood cell count & $8.5 \mathrm{k} / \mathrm{uL}(4.8-10.8)$ & $8.5 \times 10^{9} / \mathrm{L}(4.5-11.0)$ \\
\hline Hemoglobin & $7.9 \mathrm{~g} / \mathrm{dL}(12.0-16.0)$ & 79 g/L (140-175) \\
\hline Hematocrit & $23.9 \%(42 \%-51 \%)$ & 0.24 proportion of $1(0.41-0.50)$ \\
\hline Platelets & $233 \mathrm{k} / \mathrm{uL}(150-400)$ & $233 \times 10^{9} / \mathrm{L}(150-350)$ \\
\hline Sodium & $138 \mathrm{mEq} / \mathrm{L}(135-145)$ & $138 \mathrm{mmol} / \mathrm{L}(136-142)$ \\
\hline Potassium & $4.1 \mathrm{mEq} / \mathrm{L}(3.5-5.0)$ & $4.1 \mathrm{mmol} / \mathrm{L}(3.5-5.0)$ \\
\hline Chloride & $94 \mathrm{mEq} / \mathrm{L}(98-108)$ & $94 \mathrm{mmol} / \mathrm{L}(96-106)$ \\
\hline Bicarbonate & $29 \mathrm{mEq} / \mathrm{L}(24-30)$ & $29 \mathrm{mmol} / \mathrm{L}(21-28)$ \\
\hline Blood urea nitrogen & 56 mg/dL (8-26) & $19.9 \mathrm{mmol} / \mathrm{L}(2.9-8.2)$ \\
\hline Creatinine & $3.8 \mathrm{mg} / \mathrm{dL}(0.5-1.5)$ & 335 umol/L (53-106) \\
\hline Calcium & $16.6 \mathrm{mg} / \mathrm{dL}(8.5-10.5)$ & $4.15 \mathrm{mmol} / \mathrm{L}(2.05-2.55)$ \\
\hline Ionized calcium & $1.93 \mathrm{mmol} / \mathrm{L}(1.15-1.27)$ & $1.93 \mathrm{mmol} / \mathrm{L}(1.15-1.27)$ \\
\hline Magnesium & $4.6 \mathrm{mg} / \mathrm{dL}(1.5-2.7)$ & $2.30 \mathrm{mmol} / \mathrm{L}(0.65-1.05)$ \\
\hline Total protein & $7.1 \mathrm{~g} / \mathrm{dL}(5.8-8.3)$ & $71 \mathrm{~g} / \mathrm{L}(60-80)$ \\
\hline Albumin & $4.1 \mathrm{~g} / \mathrm{dL}(3.2-4.6)$ & $40 \mathrm{~g} / \mathrm{L}(35-50)$ \\
\hline AST & $15 \mathrm{U} / \mathrm{L}(9-36)$ & 0.25 ukat/L (0.17-0.51) \\
\hline ALT & $5 \mathrm{U} / \mathrm{L}(5-40)$ & 0.08 ukat/L (0.17-0.68) \\
\hline Alkaline phosphatase & $142 \mathrm{U} / \mathrm{L}(43-160)$ & 2.37 ukat/L (0.5-2.0) \\
\hline Total bilirubin & $0.2 \mathrm{mg} / \mathrm{dL}(0.2-1.1)$ & $3.42 \mathrm{umol} / \mathrm{L}(5.0-21)$ \\
\hline Direct bilirubin & $0.1 \mathrm{mg} / \mathrm{dL}(0.0-0.3)$ & $1.71 \mathrm{umol} / \mathrm{L}(1.7-5.1)$ \\
\hline
\end{tabular}

dyspnea, diaphoresis, or palpitations. On review of systems, patient denied any fever, chills, cough, abdominal pain, myalgia, arthralgia, rash, or weight loss.

Her medical comorbidities included heart failure, chronic obstructive pulmonary disease, Parkinson's disease, schizophrenia, hypertension, and diabetes mellitus. She was an exsmoker and did not use any recreational drugs or alcohol. Patient resided in a skilled nursing facility for the past two years and her family history was unknown.

Her physical examination at the time of admission revealed a disoriented and confused elderly woman. She was oriented to only her name. According to nursing home staff the patient at baseline was fully alert and oriented to name, person, and place. Initial vital signs showed temperature $98.8^{\circ} \mathrm{F}$ (37.1 degrees $\mathrm{C}$ ), pulse 65 beats per minute, respiratory rate 16 breaths per minute, and blood pressure $119 / 58 \mathrm{~mm}$ of hg, with an oxygen saturation of $100 \%$ on room air. She had dry oral mucous membranes and a poor skin turgor. Pupils were equally round and reactive to light and accommodation. There was no jugular venous distention. Chest exam showed bilateral air entry without any adventitious sounds. Cardiovascular exam showed normal heart sounds without murmurs, gallops, or rubs. Abdomen was soft, with no visceromegaly and with normal bowel sounds. Extremities were warm and well perfused without edema, cyanosis, or clubbing.

Laboratory values on admission are shown in Table 1.

The fractional excretion of sodium (Fena) was 1.2\%. Anemia workup showed serum iron $36 \mathrm{ug} / \mathrm{dL}$ (normal 60-150 ug/ $\mathrm{dL}$ and SI units: $6.44 \mathrm{umol} / \mathrm{L}(10.7-26.9))$, ferritin $329 \mathrm{ng} / \mathrm{mL}$ (normal 15-200 and SI units: $739 \mathrm{pmol} / \mathrm{L}(33-450)$ ), folate $>19.9 \mathrm{ng} / \mathrm{mL}$ (normal 3-16 and SI units: $45.09 \mathrm{nmol} / \mathrm{L}(7-36)$ ),
B12 $1364 \mathrm{pg} / \mathrm{mL}$ (normal 160-950 and SI units: $1006 \mathrm{pmol} / \mathrm{L}$ (118-701)), and transferrin saturation of $18 \%$. Workup for hypercalcemia revealed a serum PTH level of 15.8 (normal 10-65 and SI unit: $15.8 \mathrm{ng} / \mathrm{L}$ (10-650), total vitamin D 25$\mathrm{OH}$ which was $30.2 \mathrm{ng} / \mathrm{mL}$ (normal $14-60$ and SI unit $75.38 \mathrm{nmol} / \mathrm{L}(35-150)$ ), and vitamin D 1,25 dihydroxy level which was elevated at $128 \mathrm{pg} / \mathrm{mL}$ (normal 25-45 and SI units $78.5 \mathrm{pmol} / \mathrm{L}(60-108)$ ). Other pertinent laboratory values are shown in Table 2. Chest X-ray did not show any pathology. Electrocardiogram showed normal sinus rhythm with a 1st degree AV block and an old incomplete LBBB.

The patient was initially managed in the medical intensive care unit with intravenous fluids and pamidronate. The serum calcium slowly decreased from $16.6 \mathrm{mg} / \mathrm{dL}(4.15 \mathrm{mmol} / \mathrm{L})$ to $10.6 \mathrm{mg} / \mathrm{dL}(2.65 \mathrm{mmol} / \mathrm{L})$. Figure 1 shows the serum calcium trend during the hospitalization. The renal function improved from serum creatinine of $3.8 \mathrm{mg} / \mathrm{dL}$ (335 umol/L) to $2.5 \mathrm{mg} / \mathrm{dL}$ (221 umol/L).

PTH-related peptide was elevated at $45 \mathrm{pg} / \mathrm{mL}$. It was possible that this might have been a false positive because at the time of collection patient had GFR of 12 and serum creatinine of $3.9 \mathrm{mg} / \mathrm{dL}$ and PTH-related peptide can be elevated in renal disease. Considering the elevated PTHrelated peptide levels, a CT scan of the chest, abdomen, and pelvis without contrast was done which showed upper lobe bronchiectasis and a hypodense $4 \mathrm{~cm}$ lesion in left kidney. However, there was no evidence of any malignancy, lymphadenopathy, or splenomegaly. Our initial impression was likely multiple myeloma for which protein electrophoresis was done which revealed a normal serum protein electrophoresis and a urine protein electrophoresis that showed a restriction band. A bone marrow biopsy was performed 
TABLE 2: Pertinent laboratory values during hospitalization (SI units are in parenthesis).

\begin{tabular}{|c|c|c|c|c|c|c|}
\hline $\begin{array}{l}\text { Laboratory } \\
\text { test }\end{array}$ & Admission & Day 5 & Day 10 & Day 15 & Day 20 & Day 25 \\
\hline $\begin{array}{l}\text { Serum } \\
\text { calcium }\end{array}$ & $16.6(4.15 \mathrm{mmol} / \mathrm{L})$ & $10.6(2.65 \mathrm{mmol} / \mathrm{L})$ & $12.5(3.13 \mathrm{mmol} / \mathrm{L})$ & $12.9(3.23 \mathrm{mmol} / \mathrm{L})$ & $12.6(3.15 \mathrm{mmol} / \mathrm{L})$ & $12.5(3.13 \mathrm{mmol} / \mathrm{L})$ \\
\hline $\begin{array}{l}\text { Serum } \\
\text { phosphorus }\end{array}$ & $6.3(2.03 \mathrm{mmol} / \mathrm{L})$ & $2.8(0.90 \mathrm{mmol} / \mathrm{L})$ & $3.4(1.10 \mathrm{mmol} / \mathrm{L})$ & $3.4(1.10 \mathrm{mmol} / \mathrm{L})$ & $4.3(1.39 \mathrm{mmol} / \mathrm{L})$ & $5.0(1.62 \mathrm{mmol} / \mathrm{L})$ \\
\hline $\begin{array}{l}\text { Serum } \\
\text { magnesium }\end{array}$ & $4.6(2.30 \mathrm{mmol} / \mathrm{L})$ & $2.3(1.15 \mathrm{mmol} / \mathrm{L})$ & $1.6(0.80 \mathrm{mmol} / \mathrm{L})$ & $3.4(1.70 \mathrm{mmol} / \mathrm{L})$ & $1.8(0.9 \mathrm{mmol} / \mathrm{L})$ & $2.0(1.00 \mathrm{mmol} / \mathrm{L})$ \\
\hline BUN & $56(19.9 \mathrm{mmol} / \mathrm{L})$ & $30(10.7 \mathrm{mmol} / \mathrm{L})$ & $25(8.9 \mathrm{mmol} / \mathrm{L})$ & $30(10.7 \mathrm{mmol} / \mathrm{L})$ & $32(11.4 \mathrm{mmol} / \mathrm{L})$ & $54(19.2 \mathrm{mmol} / \mathrm{L})$ \\
\hline Creatinine & $3.8(335 \mathrm{umol} / \mathrm{L})$ & $2.8(247 \mathrm{umol} / \mathrm{L})$ & $2.4(212 \mathrm{umol} / \mathrm{L})$ & $2.3(203 \mathrm{umol} / \mathrm{L})$ & 1.9 (167 umol/L) & $2.1(185 \mathrm{umol} / \mathrm{L})$ \\
\hline
\end{tabular}

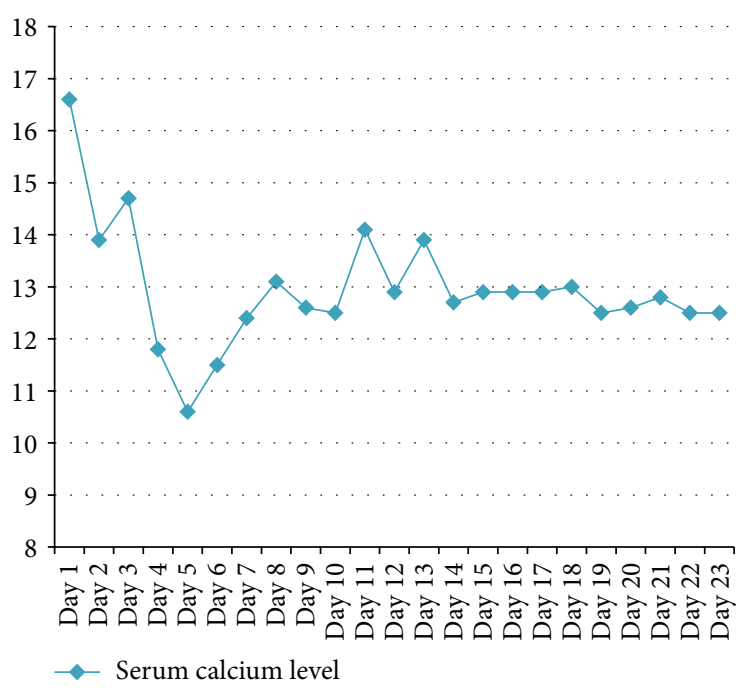

FIgURE 1: Serum calcium levels during hospitalization.

which revealed nonnecrotizing granulomas (Figures 2 and 3). Additional lab tests showed elevated serum ACE level (113 U/L) and beta-2-microglobulin $(14.3 \mathrm{mg} / \mathrm{L})$. Sputum for acid fast bacilli AFBs was sent and tuberculosis (TB) was ruled out.

Patient underwent Fiberoptic bronchoscopy with bronchoalveolar lavage and transbronchial and endobronchial biopsies. Transbronchial biopsy showed nonnecrotizing granulomatous inflammation consistent with sarcoidosis (Figure 4). The patient was started on prednisone. After receiving therapy with prednisone and hydration the calcium levels decreased and remained stable between $12 \mathrm{mg} / \mathrm{dL}$ $(3.0 \mathrm{mmol} / \mathrm{L})$ and $12.5 \mathrm{mg} / \mathrm{dL}(3.13 \mathrm{mmol} / \mathrm{L})$. Renal function and anemia level returned to baseline after receiving starting prednisone and the patient was subsequently discharged to skilled nursing facility on prednisone.

\section{Discussion}

Sarcoidosis was first described in 1899, when Boeck first coined the term "sarcoid" after his findings of "epithelioid cells with large pale nuclei and also a few giant cells" on a skin biopsy [8]. Since then it has remained an enigmatic

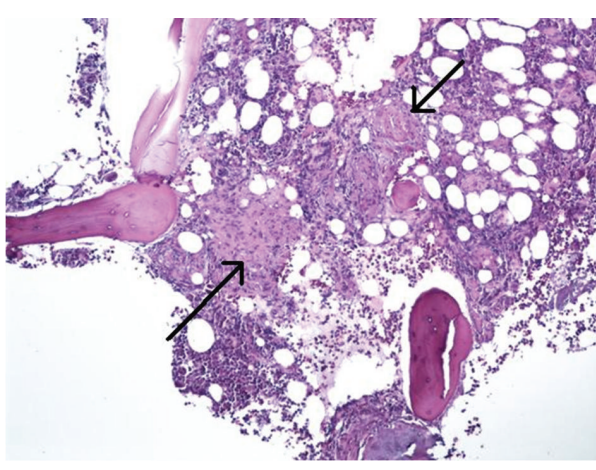

FIGURE 2: Bone marrow on low power $(\times 200)$ shows multiple compact nonnecrotizing granulomas (black arrows). The surrounding tissue is comprised of hematopoietic cells with trilineage maturation and bony trabeculae (Hematoxylin and Eosin stain).

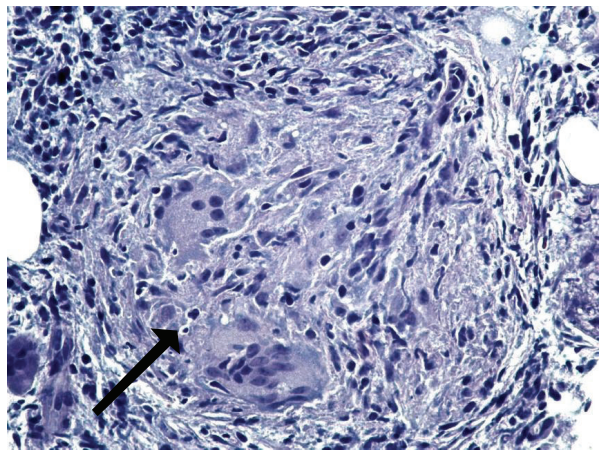

FIGURE 3: Bone marrow on high power $(\times 400)$ with well-formed nonnecrotizing granuloma (black arrow) comprised of epithelioid cells, multinucleated giant cells, scant lymphocytes, and no necrosis (Hematoxylin and Eosin stain).

multisystem granulomatous disease with significant morbidity. Sarcoidosis can affect people of all racial and ethnic backgrounds and usually develops between 20 and 39 years of age [9]. The annual incidence varies throughout the world due to differences in environmental exposures, predisposing HLA alleles, and other genetic factors. The annual incidence among African Americans is three times that among white Americans [9]. Sarcoidosis has an increase in mortality and morbidity among African Americans $[9,10]$. 


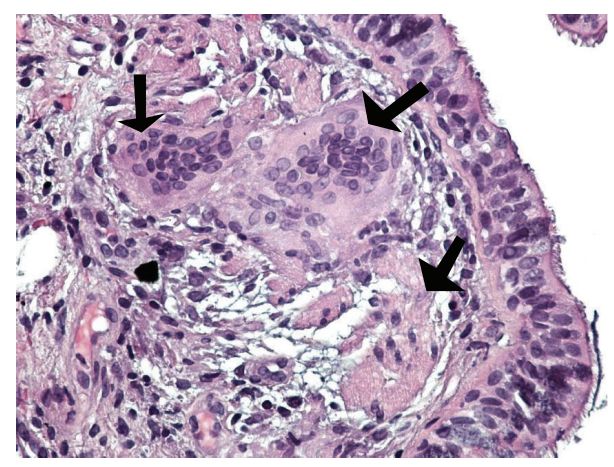

FIGURE 4: Lung peribronchial tissue on high power $(\times 400)$ showing nonnecrotizing granuloma comprised mainly of multinucleated giant cells (black arrows) and epithelioid cells. The background shows ciliated pseudostratified columnar epithelium (Hematoxylin and Eosin stain).

The pathogenesis of sarcoidosis involves an inflammatory response that leads to granuloma formation. This inflammatory response involves an interaction between an antigen, human leukocyte antigen (HLA) class II molecules, and T-cell receptors. Once an antigen(s) enters the host, it is phagocytosed by an antigen presenting cell (APC) which processes the antigen and presents it to $\mathrm{T}$-cell receptors on naïve $\mathrm{T}$ cells of $\mathrm{CD} 4+$ class. This reaction causes a polarization of T cells into a Th1 phenotype followed by proliferation and differentiation leading to formation of a granuloma. According to this process, a combination of any of the three facets, involving the interplay between antigen, HLA molecules, and T cell receptors can initiate development of granulomatous disease. Therefore, there has been interest in investigating either HLA genes, exposure to certain exogenous antigens, or T-cell immune response $[11,12]$.

Sarcoidosis typically presents with pulmonary manifestations such as bilateral hilar adenopathy (50 percent of cases), with pulmonary reticular opacities, or with skin, joint, or eye lesions. In up to 50 percent of patients, the disease is detected incidentally by radiographic abnormality. Bilateral hilar adenopathy is the most common thoracic manifestation, but 3 to 5 percent of patients with sarcoidosis can have unilateral hilar adenopathy. Pulmonary function tests often reveal restrictive ventilatory defect with a decreased diffusion capacity [13]. Sarcoidosis can involve any organ but in more than 90 percent of patients, it is manifested with pulmonary involvement. Respiratory symptoms include cough, shortness of breath, and chest discomfort. Our patient's only respiratory complaint was vague chest pain. Chest radiographs can be classified into four stages, which represent radiographic patterns and not disease chronicity. Stage 1 is bilateral hilar adenopathy without infiltration. Stage 2 is bilateral hilar adenopathy with infiltration. Stage 3 is infiltration alone. Stage 4 is fibrotic bands, bullae, hilar retraction, bronchiectasis, and diaphragmatic tenting [14]. Our patient interestingly did not have any respiratory complaints and chest radiograph did not reveal any abnormalities. Pulmonary hypertension is another well-known respiratory complication of sarcoidosis. It has been shown that the pulmonary artery pressure is high in 6 to 23 percent of patients while at rest and up to 43 percent of patients with exertion [15]. Fibrosis of the pulmonary vessels is likely the most common mechanism for pulmonary hypertension in patients with sarcoidosis. Our patient was found to have an elevated pulmonary artery pressure with an estimated pulmonary artery systolic pressure of $63 \mathrm{mmHg}$ on transthoracic echocardiograph.

While pulmonary manifestations is the most common presentation of the disease, 30 percent of patients can present with extrapulmonary manifestations involving the skin, eyes, lymph nodes, heart, kidney, and central nervous system. Our patient did not present with any pulmonary nor extrapulmonary manifestations of sarcoidosis, except for acute kidney injury. Even though our patient did not have any skin manifestations, a skin examination is important because biopsy of a cutaneous sarcoid lesion has been shown to have high diagnostic yield. Erythema nodosum signifies a good prognosis during an acute presentation. Other systemic symptoms such as fatigue, night sweat, and weight loss are also common. Lofgren's syndrome, an acute presentation that consists of erythema nodosum, arthritis, and bilateral hilar adenopathy, occurs in 9 to 34 percent of patients with sarcoidosis [16]. Cardiac sarcoidosis is found at autopsy in nearly 25 percent of patients in the United States and up to 50 percent of patients in Japan [17]. Cardiac magnetic resonance imaging is highly sensitive test for cardiac sarcoidosis and can detect minute amounts of sarcoid-related cardiac damage [18]. Neurosarcoidosis is found at autopsy in up to $25 \%$ of patients; however neurological disease is only the manifestation in 10 to 17 percent of patients with sarcoidosis [19]. Common symptoms of neurosarcoidosis include headache, ataxia, seizures, and cognitive dysfunction [20].

The diagnosis of sarcoidosis is best supported by a tissue biopsy specimen that reveals noncaseating epithelioid granulomas in a patient with clinical and radiologic findings of the disease [21]. In a patient who presents with Lofgren's syndrome, a diagnosis of sarcoidosis is reasonably certain without biopsy. In all other cases, a biopsy specimen from the organ that is most easily accessible should be obtained such as the skin or lymph nodes. Fiber optic bronchoscopy with transbronchial biopsy has a diagnostic yield of 85 percent $[13,21]$. Other initial assessments in the clinic evaluation of sarcoidosis should include pulmonary function tests, ophthalmologic evaluation, and complete blood count and measurement of electrolytes, including measurement of serum angiotensin-converting enzyme (useful to monitor patient compliance).

Skin involvement is also very common, occurring in 25 to 35 percent of patients with sarcoidosis. Lesions such as macules, papules, and plaques can be seen and usually involved the neck, upper back, trunk, and extremities. A disfiguring sarcoid-related skin lesion is Lupus pernio, which is seen as indurated, violaceous lesions on the face. Lupus pernio is more common in woman and is associated with chronic sarcoidosis [22].

An uncommon extrapulmonary involvement of sarcoidosis is hypercalcemia and renal disease. It has been shown that 10-20 percent of patient with sarcoidosis have hypercalcemia [23]. And 10 percent have renal calculi. These abnormalities 
of calcium metabolism are due to dysregulated production of 1,25-dihydroxyvitamin D by activated macrophages trapped in pulmonary alveoli and granulomatous inflammation [5, $6,24]$. 1,25-dihydroxyvitamin $\mathrm{D}$ increases serum calcium by mainly increasing intestinal calcium absorption but also acts on the bone and kidney to increase serum calcium as well [24]. In the 1970s, it was shown that 1,25-dihydroxyvitamin D levels were elevated in hypercalcemic patients with sarcoidosis and, later, Adams and colleagues showed that the increased 1,25-dihydroxyvitamin $\mathrm{D}$ levels were due to production by the pulmonary alveolar macrophages [24].

Hypercalcemia is most often caused by primary hyperparathyroidism or malignancy. However there are many other conditions to consider, such as hypocalciuric hypercalcemia, multiple myeloma, vitamin A and vitamin D intoxication, thyrotoxicosis, tuberculosis, fungal infections, thyrotoxicosis, lymphoma, and sarcoidosis. Causes can be divided into PTH-mediated (high or normal PTH levels) and non-PTH mediated. In PTH mediated hypercalcemia the two differential diagnoses to consider are primary hyperparathyroidism and familial hypocalciuric hypercalcemia. These entities are differentiated bases upon urinary calcium level. Elevated urinary calcium in a patient with PTH mediated hypercalcemia signifies primary hyperparathyroidism. The differential is much broader in non-PTH mediated hypercalcemia and requires measurement of PTH-related peptide levels, 1,25 vitamin D, vitamin $25 \mathrm{OH}$. An elevated PTH-related peptide in non-PTH mediated hypercalcemia indicates malignancy as the cause of hypercalcemia. An elevated 1,25 vitamin D level in non-PTH mediated hypercalcemia indicates lymphoma or granulomatous disease. If PTH-related peptide and 1,25 vitamin D levels are normal, then next step requires measurement of vitamin $25 \mathrm{OH}$, SPEP, UPEP, TSH, and vitamin A levels. Other miscellaneous causes of hypercalcemia to consider are chronic lithium therapy, thiazide diuretics, adrenal insufficiency, and rhabdomyolysis $[25,26]$.

The incidence and prevalence of renal involvement in sarcoidosis remains unclear [27]. It has been suggested that renal involvement occurs in 35 to 50 percent of patients of sarcoidosis $[27,28]$. Primary renal manifestations are nephrolithiasis, nephrocalcinosis, and acute interstitial nephritis with or without granuloma formation. The nephrocalcinosis and nephrolithiasis are due to hypercalcemia resulting from increased GI absorption of calcium due to increased 1,25dihydroxyvitamin D levels by activated mononuclear cells. Nephrolithiasis and nephrocalcinosis may be initial presenting feature of sarcoidosis [29]. However, only 2 to $3 \%$ of patients with sarcoidosis will present with nephrolithiasis as the first manifestation [29]. The stones are typically composed of calcium oxalate. Patients with nephrocalcinosis may present with elevated creatinine and a benign urinalysis. These patients may have polyuria, which may be due to central diabetes insipidus from granulomatous infiltration of the hypothalamus [30]. It has been shown that glucocorticoids can improve calcium metabolism in patients with sarcoidosis. The other renal lesion associated with sarcoidosis is interstitial nephritis, which occurs in 20 percent of patients with sarcoidosis [31]. However, sarcoid-related interstitial nephritis is typically seen during the initial presentation of sarcoidosis and rarely in patients with long-standing sarcoidosis [32]. The urinary manifestations of sarcoid nephritis are nonspecific as the urinalysis is typical of chronic tubulointerstitial diseases [33]. The diagnosis of sarcoid nephritis is suggested by a renal biopsy which reveals normal glomeruli and interstitial infiltration with mononuclear cells and noncaseating granulomas in the interstitium $[32,33]$. The findings are suggestive, but not diagnostic, of sarcoidosis. Sarcoid nephritis is a disease of exclusion; therefore other etiologies of interstitial nephritis must be ruled out and there must be extrarenal manifestations of granulomatous disease to be confident about diagnosis of sarcoid nephritis. Patients with sarcoidosis may occasionally also present with glomerular disease; however the relationship to sarcoidosis has not been proven. In all the types of renal lesions caused by sarcoidosis, glucocorticoids have been shown to improve renal function [32].

The cornerstone of treatment of hypercalcemia due to sarcoidosis is glucocorticoids. Prednisone, $15-25 \mathrm{mg} / \mathrm{day}$, is the drug of choice to reduce the overproduction of 1,25dihydroxyvitamin $\mathrm{D}$ levels. In addition, reducing calcium intake (to under $400 \mathrm{mg} /$ day), reducing oxalate intake, and avoiding sun exposure are also recommended in treatment of hypercalcemia in granulomatous disease. Chloroquine is one alternative therapy that may also be considered [34]. Although the mechanism in unclear, it is shown to impair granuloma formation. However retinal toxicity is the major concern with the use of chloroquine, although hydroxychloroquine carries less risk of retinopathy. Ketoconazole is another alternative to glucocorticoids [35].

This was a rare case of a patient with an unusual presentation of sarcoidosis with hypercalcemia, anemia, and acute kidney injury being the initial presentation. Hypercalcemia is rarely a presenting manifestation, with clinically significant hypercalcemia occurring in less than $5 \%$ of patients. Awareness about variegated presentation of sarcoidosis will prompt early institution of targeted therapy and prevent long-term sequelae of this potentially fatal condition.

\section{Conflict of Interests}

The authors do not have a direct financial relation with the commercial identities mentioned in the paper that might lead to a conflict of interests.

\section{Authors' Contribution}

All authors have made contributions to the paper and have reviewed it before submission.

\section{References}

[1] D. Valeyre, A. Prasse, H. Nunes, Y. Uzunhan, P.-Y. Brillet, and J. Müller-Quernheim, "Sarcoidosis," The Lancet, vol. 383, no. 9923, pp. 1155-1167, 2014.

[2] R. Karnchanasorn, M. Sarikonda, S. Aldasouqi, and V. V. Gossain, "Severe hypercalcemia and acute renal failure: an unusual 
presentation of sarcoidosis," Case Reports in Medicine, vol. 2010, Article ID 423659, 5 pages, 2010.

[3] J. S. Adams, "Vitamin D metabolite-mediated hypercalcemia," Endocrinology and Metabolism Clinics of North America, vol. 18, no. 3, pp. 765-778, 1989.

[4] O. P. Sharma, "Vitamin D, calcium, and sarcoidosis," Chest, vol. 109, no. 2, pp. 535-539, 1996.

[5] J. S. Adams, F. R. Singer, M. A. Gacad et al., "Isolation and structural identification of 1,25-dihydroxyvitamin D3 produced by cultured alveolar macrophages in sarcoidosis," Journal of Clinical Endocrinology and Metabolism, vol. 60, no. 5, pp. $960-$ 966, 1985.

[6] H. J. Zeimer, T. M. Greenaway, J. Slavin et al., "Parathyroidhormone-related protein in sarcoidosis," The American Journal of Pathology, vol. 152, no. 1, pp. 17-21, 1998.

[7] R. P. Baughman, A. S. Teirstein, M. A. Judson et al., "Clinical characteristics of patients in a case control study of sarcoidosis," American Journal of Respiratory and Critical Care Medicine, vol. 164, no. 10, pp. 1885-1889, 2001.

[8] C. Boeck, "Multiple benign sarcoid of the skin," Journal of Cutaneous and Genitourinary Diseases, vol. 17, pp. 543-550, 1899.

[9] B. A. Rybicki, M. Major, J. Popovich Jr., M. J. Maliarik, and M. C. Iannuzzi, "Racial differences in sarcoidosis incidence: a 5-year study in a health maintenance organization," American Journal of Epidemiology, vol. 145, no. 3, pp. 234-241, 1997.

[10] M. Mirsaeidi, R. F. Machado, D. Schraufnagel, N. J. Sweiss, and R. P. Baughman, "Racial difference in sarcoidosis mortality in the United States," Chest, vol. 147, no. 2, pp. 438-449, 2015.

[11] P. D. Thomas and G. W. Hunninghake, "Current concepts of the pathogenesis of sarcoidosis," American Review of Respiratory Disease, vol. 135, no. 3, pp. 747-760, 1987.

[12] R. P. Baughman, D. A. Culver, and M. A. Judson, "A concise review of pulmonary sarcoidosis," American Journal of Respiratory and Critical Care Medicine, vol. 183, no. 5, pp. 573-581, 2011.

[13] M. A. Judson, B. W. Thompson, D. L. Rabin et al., "The diagnostic pathway to sarcoidosis," Chest, vol. 123, no. 2, pp. 406-412, 2003.

[14] A. S. Morgenthau and M. C. Iannuzzi, "Recent advances in sarcoidosis," Chest, vol. 139, no. 1, pp. 174-182, 2011.

[15] K. A. Fisher, D. M. Serlin, K. C. Wilson, R. E. Walter, J. S. Berman, and H. W. Farber, "Sarcoidosis-associated pulmonary hypertension: outcome with long-term epoprostenol treatment," Chest, vol. 130, no. 5, pp. 1481-1488, 2006.

[16] L. E. Siltzbach, D. G. James, E. Neville et al., "Course and prognosis of sarcoidosis around the world," The American Journal of Medicine, vol. 57, no. 6, pp. 847-852, 1974.

[17] J. S. Kim, M. A. Judson, R. Donnino et al., "Cardiac sarcoidosis," American Heart Journal, vol. 157, no. 1, pp. 9-21, 2009.

[18] M. R. Patel, P. J. Cawley, J. F. Heitner, and et al, "Detection of myocardial damage in patients with sarcoidosis," Circulation, vol. 120, no. 20, pp. 1969-1977, 2009.

[19] C. Kellinghaus, M. Schilling, and P. Lüdemann, "Neurosarcoidosis: clinical experience and diagnostic pitfalls," European Neurology, vol. 51, no. 2, pp. 84-88, 2004.

[20] E. E. Lower and K. L. Weiss, "Neurosarcoidosis," Clinics in Chest Medicine, vol. 29, no. 3, pp. 475-492, 2008.

[21] "Statement on sarcoidosis. Joint Statement of the American Thoracic Society (ATS), the European Respiratory Society
(ERS) and the World Association of Sarcoidosis and Other Granulomatous Disorders (WASOG) adopted by the ATS Board of Directors and by the ERS Executive Committee, February 1999," American Journal of Respiratory and Critical Care Medicine, vol. 160, no. 2, pp. 736-755, 1999.

[22] H. Yanardağ, Ö. N. Pamuk, and G. E. Pamuk, "Lupus pernio in sarcoidosis: clinical features and treatment outcomes of 14 patients," Journal of Clinical Rheumatology, vol. 9, no. 2, pp. 7276, 2003.

[23] M. F. Holick, "Vitamin D deficiency," The New England Journal of Medicine, vol. 357, no. 3, pp. 266-281, 2007.

[24] J. S. Adams, S.-Y. Ren, J. E. Arbelle et al., "Regulated production and intracrine action of 1,25-dihydroxyvitamin D3 in the chick myelomonocytic cell line HD-11," Endocrinology, vol. 134, no. 6, pp. 2567-2573, 1994.

[25] T. P. Jacobs and J. P. Bilezikian, "Clinical review: rare causes of hypercalcemia," Journal of Clinical Endocrinology \& Metabolism, vol. 90, no. 11, pp. 6316-6322, 2005.

[26] F. W. Lafferty, "Differential diagnosis of hypercalcemia," Journal of Bone and Mineral Research, vol. 6, supplement 2, pp. S51-S59, 1991.

[27] E. Lebacq, V. Desmet, and H. Verhaegen, "Renal involvement in sarcoidosis," Postgraduate Medical Journal, vol. 46, no. 538, pp. 526-529, 1970.

[28] K. W. Berger and A. S. Relman, "Renal impairment due to sarcoid infiltration of the kidney; report of a case proved by renal biopsies before and after treatment with cortisone," The New England Journal of Medicine, vol. 252, p. 44, 1955.

[29] G. Rizzato, P. Fraioli, and L. Montemurro, "Nephrolithiasis as a presenting feature of chronic sarcoidosis," Thorax, vol. 50, no. 5, pp. 555-559, 1995.

[30] C. A. Stuart, F. A. Neelon, and H. E. Lebovitz, "Disordered control of thirst in hypothalamic-pituitary sarcoidosis," The New England Journal of Medicine, vol. 303, no. 19, pp. 1078-1082, 1980.

[31] D. R. J. Singer and D. J. Evans, "Renal impairment in sarcoidosis: granulomatous nephritis as an isolated cause (two case reports and review of the literature)," Clinical Nephrology, vol. 26, no. 5, pp. 250-256, 1986.

[32] A. R. Berliner, M. Haas, and M. J. Choi, "Sarcoidosis: the Nephrologist's perspective," American Journal of Kidney Diseases, vol. 48, no. 5, pp. 856-870, 2006.

[33] M. Mahévas, F. X. Lescure, J.-J. Boffa et al., "Renal sarcoidosis: clinical, laboratory, and histologic presentation and utcome in 47 patients," Medicine, vol. 88, no. 2, pp. 98-106, 2009.

[34] B. J. Hunt and E. R. Yendt, "The response of hypercalcemia in sarcoidosis to chloroquine," Annals of Internal Medicine, vol. 59, pp. 554-564, 1963.

[35] J. S. Adams, O. P. Sharma, M. M. Diz, and D. B. Endres, "Ketoconazole decreases the serum 1,25-dihydroxyvitamin D and calcium concentration in sarcoidosis-associated hypercalcemia," The Journal of Clinical Endocrinology \& Metabolism, vol. 70, no. 4, pp. 1090-1095, 1990. 


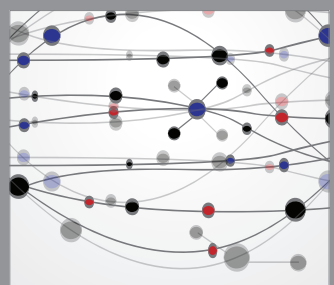

The Scientific World Journal
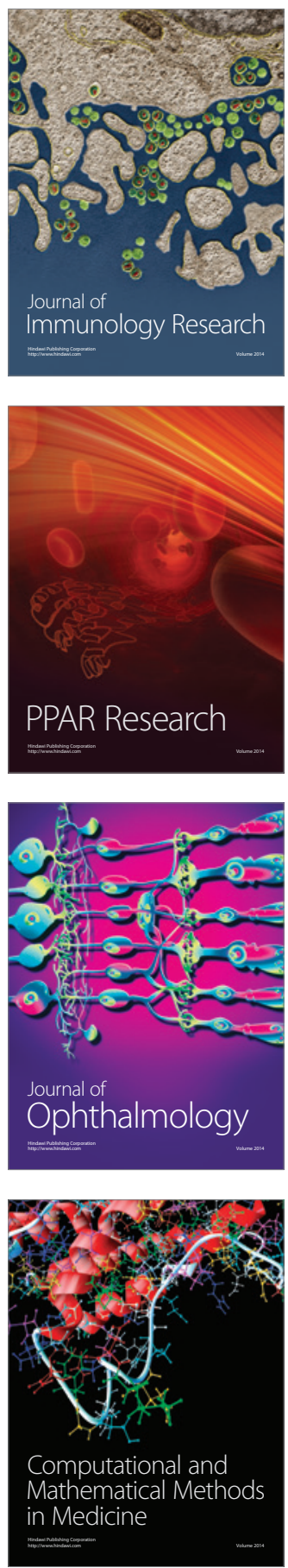

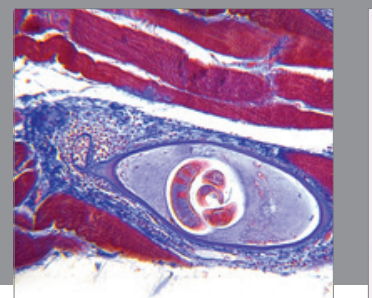

Gastroenterology

Research and Practice
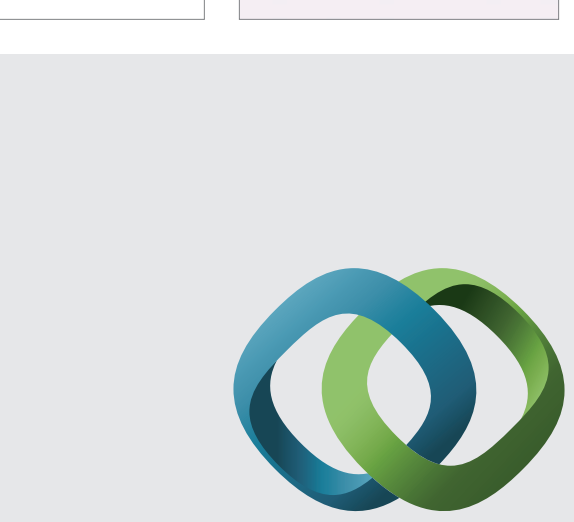

\section{Hindawi}

Submit your manuscripts at

http://www.hindawi.com
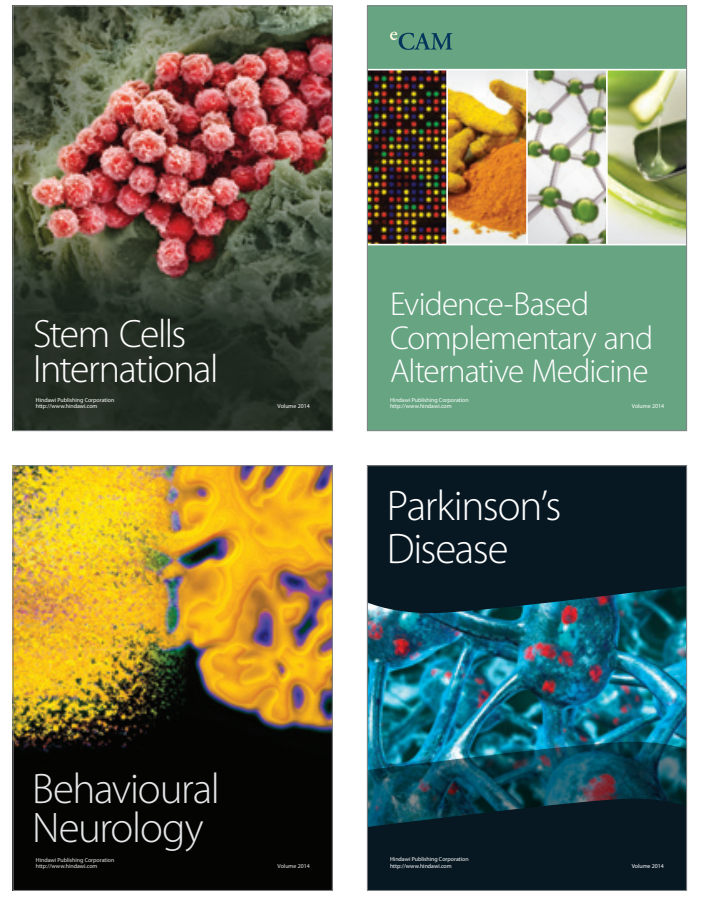
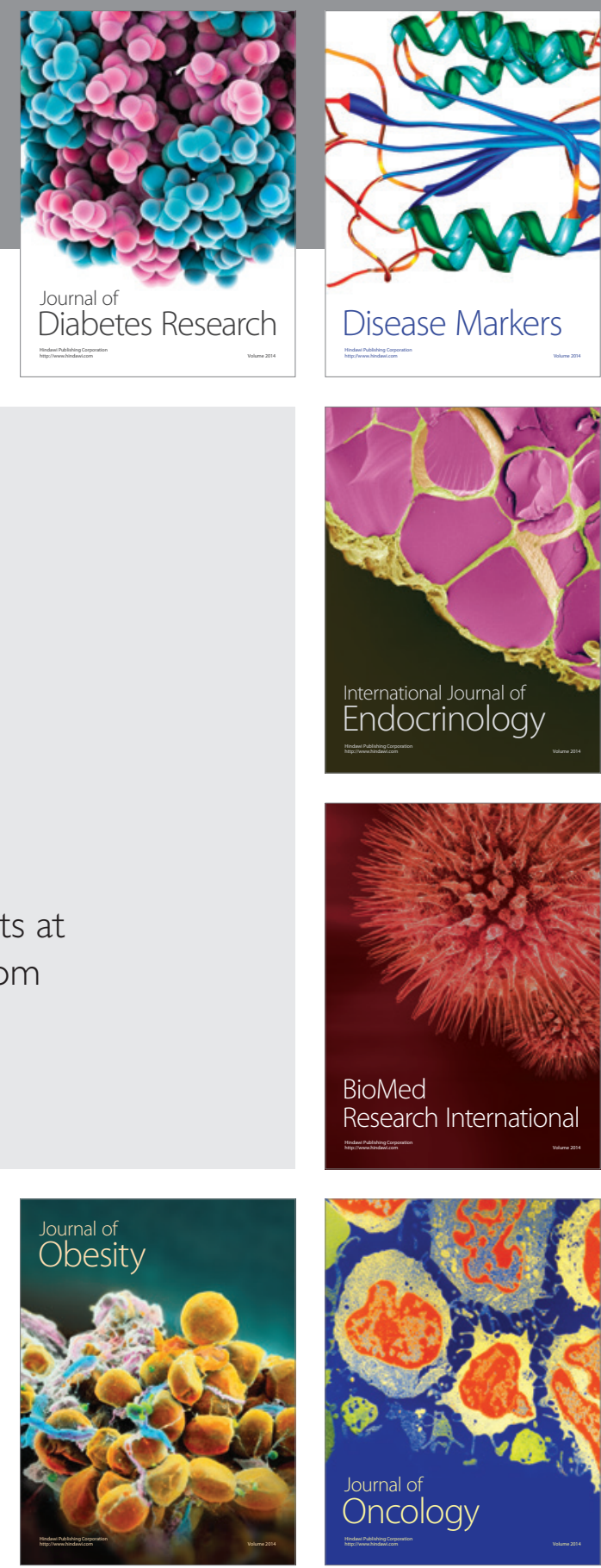

Disease Markers
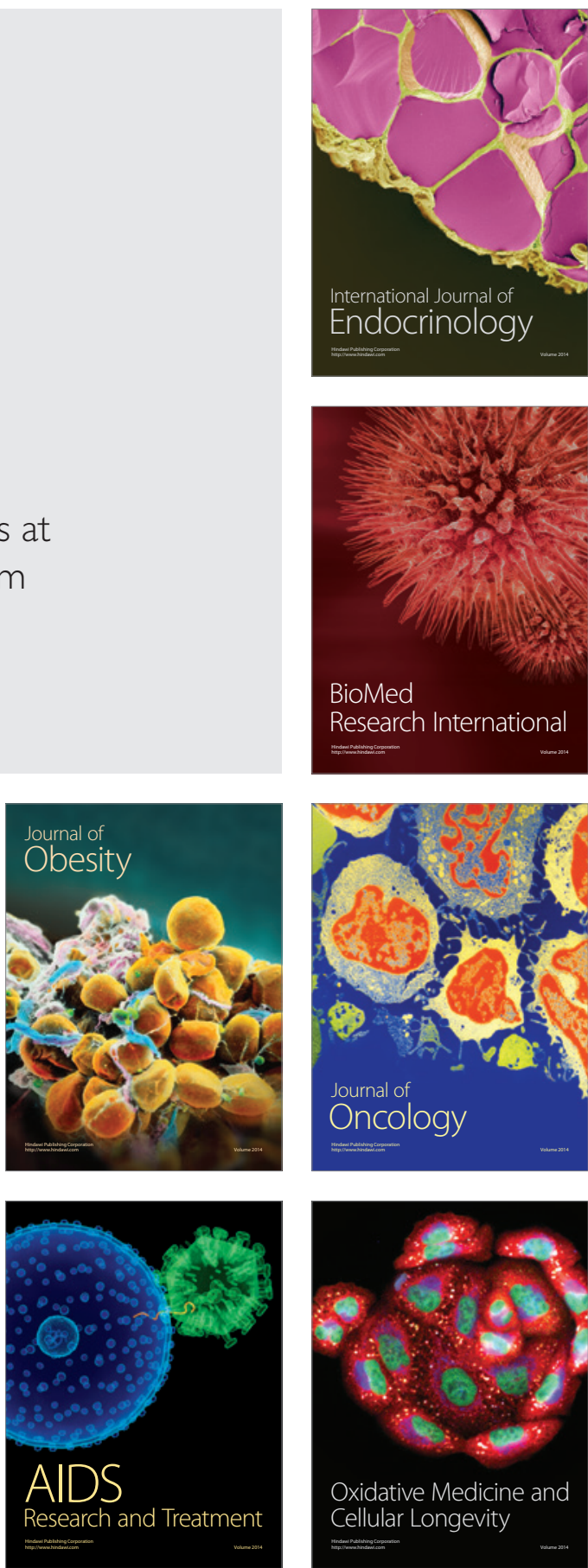